
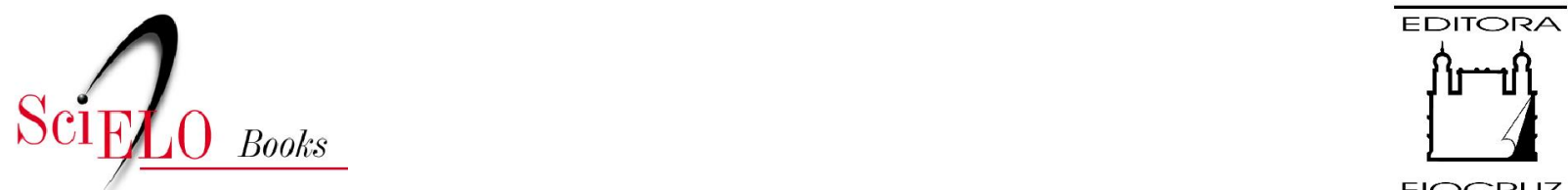

FIOCRUZ

\title{
9. Drogas
}

o desafio da saúde pública

\section{Pedro Gabriel Delgado}

\section{SciELO Books / SciELO Livros / SciELO Libros}

DELGADO, PG. Drogas: o desafio da saúde pública. In: ACSELRAD, G. org. Avessos do prazer: drogas, Aids e direitos humanos [online]. 2nd ed. rev. and enl. Rio de Janeiro: Editora FIOCRUZ, 2005, pp. 165-181. ISBN: 978-85-7541-536-8. Available from: doi: 10.7476/9788575415368. Also available in ePUB from: http://books.scielo.org/id/bgqvf/epub/acselrad-9788575415368.epub

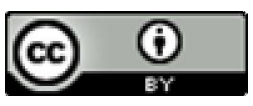

All the contents of this work, except where otherwise noted, is licensed under a Creative Commons Attribution $\underline{4.0 \text { International license. }}$

Todo o conteúdo deste trabalho, exceto quando houver ressalva, é publicado sob a licença Creative Commons Atribição 4.0.

Todo el contenido de esta obra, excepto donde se indique lo contrario, está bajo licencia de la licencia $\underline{\text { Creative }}$ Commons Reconocimento 4.0. 


\section{DROGAS:}

O DESAFIO DA SAÚDE PÚBLICA

\section{Pedra Gabriel Delgado}

\section{A Dívida Histórica da Saúde pública com a Questão do Álcool e outras Drogas}

As políticas públicas direcionadas ao problema do consumo prejudicial das drogas mostravam, em nosso país, até recentemente, uma notável rarefação de iniciativas consistentes e regulares por parte da saúde pública. A tradicional divisão das drogas em lícitas e ilícitas produzia o efeito de concentrar toda a preocupação visível do governo e da sociedade no 'combate' às substâncias consideradas ilegais, reservando lugar secundário para o álcool e o tabaco, justamente aquelas mais danosas à saúde da população. Nessa divisão pouco racional do esforço das políticas governamentais, cabia à saúde pública um papel muito discreto. Por serem ilícitas, a prevenção e o tratamento do consumo prejudicial de maconha e cocaína, por exemplo, ficavam sobrepostos pela repressão do consumo e pela pedagogia da abstinência, exercidas por uma coordenação de esforços de diversos setores do governo, centralizada na repressão ao tráfico ilícito e ao consumo, na lavagem de dinheiro, na proteção de fronteiras, no combate ao comércio clandestino, em campanhas educativas que erigiam as drogas em mal absoluto a ser extirpado do ambiente cultural etc. A saúde pública ficava em um território de sombra, vagamente direcionada ao tema do consumo prejudicial do álcool. Na composição dos órgãos intersetoriais, o espaço da saúde pública era restrito, muitas vezes reduzido à simples apreciação técnica de demandas apresentadas por entidades da sociedade civil, filantrópicas e outras. Assim foi desde o Conselho Nacional de Entorpecentes (Confen), e prosseguiu até recentemente. Mesmo em relação ao tabaco, a pouca ousadia da saúde pública era particularmente notável, tanto que, quando, na última década, tomou-se uma real decisão política de 
incorporar a redução da demanda por tabaco como item prioritário das ações preventivas, os resultados positivos foram imediatos e indiscutíveis. Hoje, pode-se dizer que o Brasil tem uma política consistente para o problema do fumo, mesmo que seus resultados ainda estejam muito aquém do esperado.

Quanto ao álcool, se ele passava ao largo dos debates dos colegiados 'antidroga', também na saúde pública não era seriamente enfrentado. Alguns esforços buscaram se consolidar, como nos anos 70, por meio do Pisam Programa de Interiorização das Ações de Saúde Mental, mas tiveram quase nenhum impacto, e ficaram reduzidos a algumas experiências localizadas. De maneira geral, admitia-se tacitamente uma incapacidade da saúde pública de lidar com problema tão grave, destinando-se aos pacientes com transtornos graves pelo consumo do álcool a internação em hospitais psiquiátricos ou o esforço silencioso dos mais de seis mil grupos anônimos de ajuda mútua. As iniciativas de restrição e controle do consumo, da propaganda, do acesso, eram escassas e de quase nenhum impacto: chegou-se ao extremo de se aprovar uma lei, a n. 9.294, de 1996, que, de alguma forma, protege do controle alguns tipos de bebida, como a cerveja, de extenso e crescente consumo, especialmente entre grupos vulneráveis, como os jovens.

Para as drogas ilícitas, a legislação em vigor desde 1976 produz o resultado catastrófico de acrescentar, aos danos reais do consumo prejudicial, a mão pesada da criminalização do uso, permitindo que se envie para a prisão ou para os hospitais de custódia um número crescente de jovens consumidores, e sendo responsável pelas taxas epidêmicas de mortalidade entre jovens de 14 a 24 anos, em função da violência associada ao comércio clandestino. $\mathrm{Na}$ ausência da saúde pública, a resposta para o tratamento dos dependentes era oferecida por instituições de caráter filantrópico e/ou religioso, incapazes de oferecer a cobertura adequada diante da magnitude epidemiológica do problema.

Diante de tudo isso, o grande desafio é de fato transpor o deserto de iniciativas e construir a política pública consistente, sustentável e efetiva, que possa articular os esforços intersetoriais, no marco da saúde pública, da democracia e da promoção dos direitos humanos.

Em 2003, o Ministério da Saúde, ouvindo diversas entidades e as instâncias do SUS, elaborou o documento A Política do Ministério da Saúde para Atenção Integral a Usuários de Álcool e Outras Drogas. As diretrizes e princípios preconizados pelo Ministério da Saúde na abordagem da questão de álcool e outras drogas estão contidos nesse documento e pautam as ações de promoção à saúde, prevenção e atenção desenvolvidas pelo órgão. A compreensão das estratégias de redução de danos como alternativas eficazes no tratamento e na prevenção; a avaliação - baseada em dados epidemiológicos - de que o 
álcool é o grande problema de saúde pública; a necessidade de incluir os usuários/dependentes de álcool e drogas em uma rede ampliada de cuidados (que extrapolem o campo da saúde); a consciência da urgência de adaptar a legislação vigente sobre álcool e outras drogas aos objetivos da saúde pública e não aos da punição são exemplos de fundamentos que norteiam as iniciativas do Ministério da Saúde acerca deste tema.

Outra iniciativa relevante e inédita foi a realização do I Encontro Brasileiro dos Centros de Atenção Psicossocial Álcool e Drogas (CAPS-AD), em abril de 2004, em Santo André, SP. Representantes de todos CAPS-AD cadastrados foram convidados para discutir seus impasses e soluções, em uma intensa troca de experiências com colegas de outros serviços, construindo uma agenda marcada pela organização de serviços, pela garantia do acesso ao atendimento e pela efetividade da cobertura dentro do território.

O governo atual vem buscando construir uma política democrática e efetiva para o tema das drogas, e de tal esforço é exemplo a articulação, inédita, de um programa de diversos agentes governamentais e da sociedade, relacionado às bebidas alcoólicas.

\section{Álcool e Redução de Danos: construindo UMA POLITICA INTERSETORIAL EFETIVA ${ }^{1}$}

"Aprecie com moderação." Essa mensagem aparece muito fugazmente no final das vibrantes e ostensivas peças publicitárias que prometem sucesso pessoal, profissional, sexual e esportivo aos jovens que consomem com volúpia, pelo gargalo, a cerveja irresistível da propaganda na TV. O público-alvo é, evidentemente, adolescentes e jovens, que nos últimos 15 anos fizeram duplicar o consumo e a produção de cerveja, no Brasil. A legislação brasileira (Lei n. 9.294/96) distingue a cerveja dos destilados e dos vinhos, para efeito de controle da propaganda. Os destilados só podem ser anunciados depois das 21 horas, mas contam com um aliado de peso, o preço: a aguardente brasileira é uma das mais baratas do mundo, custando $\mathrm{R} \$ 1,50$ (meio dólar) o litro. A venda é livre, mesmo nas cercanias de escolas e no interior dos campi universitários, ou postos de gasolina, apesar de normas restritivas cuja ineficácia é tolerada. "Aprecie com moderação." Em metade dos casos, os acidentes de

\footnotetext{
1 Esta parte constitui versão modificada de artigo escrito em colaboração com Paulo Roberto Aranha de Macedo, Francisco Cordeiro e Sueli Moreira, da Coordenação de Saúde Mental do Ministério da Saúde, e publicado em BUNING et al. Álcoole Redução de Danos: um enfoque inovador para países em transição. Brasília: Ministério da Saúde, 2003.
} 
trânsito com vítimas estão associados ao consumo de álcool, e o delicado tema da vinculação de eventos de violência intrafamiliar e urbana ao uso abusivo de bebidas alcoólicas é iluminado por evidências objetivas de estudos epidemiológicos recentes.

O uso prejudicial de álcool é, de longe, o principal problema de saúde pública no campo das drogas. Muito mais do que no caso das drogas ilícitas, a ausência de uma política pública para o álcool, abrangente, não-repressiva, atenta às complexidades culturais do problema, ousada no enfrentamento das pressões do mercado, constitui lacuna a ser urgentemente sanada. A demissão da responsabilidade do Estado nessa área é histórica e estrutural: a prevenção é errática e ineficaz, a legislação cede às pressões do mercado, a rede pública de saúde responde de maneira inadequada ao problema, com a danosa internação em hospitais psiquiátricos, as ações de redução de danos são incipientes e pontuais. A tolerância com a venda, propaganda e pressões do mercado de bebida convive com a passividade diante do problema de saúde pública e com a cruel intolerância com os usuários que precisam de tratamento.

A adoção do paradigma da redução de danos aparece como portadora de grande potencialidade. Mais grave que a passividade diante do problema seria uma equivocada proposta repressiva e 'antialcoólica'. Apenas de 10 a $15 \%$ da população geral não fazem uso de álcool durante a vida, inscrito milenarmente na cultura. Entre 60 e $70 \%$ usam bebidas alcoólicas de modo não prejudicial à saúde e ao bem-estar social, mas podem eventualmente delas fazer uso de maneira nociva. E em torno de um terço ou $30 \%$ da população apresentam problemas, de maior ou menor gravidade, com o uso de bebidas alcoólicas, entre os quais $10 \%$ da população geral apresentam sinais de dependência. Diferentemente do caso do tabaco, não tem sentido uma política que busque o fim do consumo da substância. Daí a importância do modelo de redução de danos, capaz de permitir uma abordagem abrangente, criativa e democrática para a questão.

Primeiro passo: articular as diversas áreas do governo - saúde, educação, gestão do espaço urbano e do trânsito, agricultura, fazenda, justiça - para construírem, em discussão permanente com os segmentos sociais implicados, as linhas gerais da política intersetorial.

\section{GraVidade da Questão do Álcool no Brasil}

Historicamente, a questão do uso prejudicial de álcool tem sido abordada por uma ótica predominantemente psiquiátrica ou médica. As implicações 
sociais, psicológicas, econômicas e políticas são evidentes, e devem ser consideradas na compreensão global do problema. A ausência de priorização, por parte do Ministério da Saúde (MS), de uma política de saúde integral dirigida ao consumidor de álcool e outras drogas pode ser percebida a partir do impacto econômico e social que tem recaído sobre o Sistema Único de Saúde (SUS).

A reafirmação histórica do papel nocivo do álcool deu origem a uma gama extensa de respostas políticas para o enfrentamento dos problemas decorrentes de seu consumo, corroborando assim o fato concreto da expressiva magnitude do problema, no contexto de saúde pública mundial.

Segundo a Organização Mundial de Saúde (OMS, 2001), cerca de 10\% das populações dos centros urbanos de todo o mundo consomem abusivamente substâncias psicoativas, independentemente de idade, sexo, nível de instrução e poder aquisitivo. A despeito do uso de substâncias psicoativas de caráter ilícito, e considerando qualquer faixa etária, o uso indevido de álcool e tabaco tem a maior prevalência global, trazendo também as mais graves conseqüências para a saúde pública mundial. Estudo conduzido pela Universidade de Harvard e instituições colaboradoras (Murray \& Lopez, 1996) sobre a carga global de doenças trouxe a estimativa de que o álcool seria responsável por cerca de $1,5 \%$ de todas as mortes no mundo, bem como por 2,5\% do total de anos de vida comprometidos por algum tipo de incapacidade (disability-adjusted life years Daly, um indicador da carga global de doença). Ainda segundo o mesmo estudo, essa carga inclui transtornos físicos (cirrose hepática, miocardiopatia alcoólica etc.) e lesões decorrentes de acidentes (industriais e automobilísticos, por exemplo) influenciados pelo uso indevido de álcool, o qual cresce de forma preocupante em países em desenvolvimento (Brasil, 2003).

Diante dessa preocupação, vale mencionar o I Levantamento Domiciliar sobre o Uso de Drogas Psicotrópicas no Brasil, realizado pelo Centro Brasileiro de Informações sobre Drogas Psicotrópicas, envolvendo as 107 maiores cidades do país, o qual revelou que $68,7 \%$ das pessoas fazem uso na vida de álcool e estima que $11,2 \%$ da população são dependentes de bebidas alcoólicas (Carlini et al., 2002).

Existe uma tendência mundial que aponta para o uso cada vez mais precoce de substâncias psicoativas, incluindo o álcool, sendo que tal uso também ocorre de forma cada vez mais pesada. No Brasil, pesquisa do Centro Brasileiro de Informações sobre Drogas Psicoativas (Cebrid) sobre o uso indevido de drogas por estudantes $(\mathrm{n}=2.730)$ dos antigos $1^{\underline{0}}$ e $2^{\underline{0}}$ graus em dez capitais brasileiras (Galduróz et al., 1997) revelou percentual altíssimo de adolescentes que já haviam feito uso de álcool na vida: 74,1\%. Quanto a uso 
freqüente, e para a mesma amostra, chegamos a 14,7\%. Constatou-se que $19,5 \%$ dos estudantes faltaram à escola, após beber, e que 11,5\% brigaram sob o efeito do álcool.

Entre outros aspectos importantes a destacar está a relação entre uso de álcool e acidentes de trânsito, comprovada em diversos estudos. Os dados da pesquisa realizada em Recife, Brasília, Curitiba e Salvador (Melcop et al., 1997) revelam que $61 \%$ das pessoas envolvidas em acidentes de trânsito apresentavam alcoolemia positiva. Já entre aqueles que sofreram atropelamentos, 56,2\% apresentavam algum nível de álcool no sangue. Quando foram pesquisados os acidentados por colisão e capotagem, verificaram-se as maiores proporções de presença de álcool, 71,1\% e 63,6\% das pessoas, respectivamente. Outra pesquisa, realizada no carnaval de 1997 no Recife, verificou a presença de álcool em 88,2\% das vítimas fatais de acidentes de trânsito (Melcop \& Oliveira, 1997).

Pesquisa encomendada pelo governo federal sobre os custos dos acidentes de trânsito no Brasil (Ipea, MS e colaboradores, em desenvolvimento), mostra em seus resultados preliminares que $53 \%$ do total dos pacientes atendidos por acidentes de trânsito no Ambulatório de Emergência do Hospital das Clínicas de São Paulo, em período determinado, estavam com índices de alcoolemia em seus exames de sangue superiores aos permitidos pelo Código de Trânsito Brasileiro; desses pacientes, a maioria era do sexo masculino, com idades entre 15 e 29 anos. A 'deseconomia' relacionada a esses agravos faz com que o SUS gaste aproximadamente $\mathrm{R} \$ 1.000 .000,00$ dos recursos do Tesouro Nacional e do Seguro Obrigatório de Danos Pessoais por Veículos Automotores Terrestres/DPVAT, com internações e tratamentos (Ipea, MS e colaboradores, em desenvolvimento). A mortalidade chega a 30 mil óbitos/ano, cerca de $28 \%$ das mortes por todas as causas externas. Das análises em vítimas fatais (IML/SP), o nível de alcoolemia encontrado chega a 96,8\%.

Aproximadamente $20 \%$ dos pacientes tratados na rede primária bebem em um nível considerado de alto risco, pelo menos fazendo uso abusivo do álcool. Essas pessoas têm seu primeiro contato com os serviços de saúde por intermédio de clínicos gerais. Apesar disso, estes pouco detectam a presença de acometimento por tal uso, o que tem repercussão negativa sobre as possibilidades de diagnóstico e tratamento. Vemos que, no geral, o foco da atenção está voltado para as doenças clínicas decorrentes da dependência - que ocorrem tardiamente -, e não para a dependência subjacente (Brasil, 2003).

Os fatos acima assumem importância maior dentro de um contexto preventivo quando consideramos que, via de regra, o período médio entre o primeiro problema decorrente do uso de álcool e a primeira intervenção vol- 
tada para este problema é de cinco anos; a demora para iniciar o tratamento e a sua inadequação pioram o prognóstico (Brasil, 2003).

O diagnóstico e tratamento precoces da dependência ao álcool têm papel fundamental no prognóstico desse transtorno, o que se amplia em uma perspectiva global de prevenção e promoção da saúde, e se agrava ao constatarmos, de uma forma geral, o despreparo significativo e a desinformação das pessoas que lidam diretamente com o problema, sejam elas usuários, familiares ou profissionais da saúde.

Ao analisarmos alguns dados correlatos e relativos aos custos, vemos que os custos decorrentes do consumo de álcool são de grande magnitude. Considerando dados referentes ao período de janeiro a novembro de 2003 (Datasus, 2004), tivemos na rede psiquiátrica do SUS 76.981 internações para o tratamento de problemas relacionados ao uso do álcool, mais de três vezes o número de internações ocorridas por uso de outras drogas. No mesmo período, foram emitidas 108.286 Autorizações de Internação Hospitalar (AIHs), para as internações relacionadas ao alcoolismo. Como a média de permanência em internação foi de 26,3 dias para o período selecionado, essas internações tiveram em 2003 um custo superior a 55 milhões de reais para o SUS.

Esses números não incluem os gastos com os tratamentos ambulatoriais, nem com as internações e outras formas de tratamento de doenças indiretamente provocadas pelo consumo do álcool, como aquelas que atingem os aparelhos digestivo e cardiovascular, câncer (principalmente hepático, de estômago e de mama), deficiências nutricionais, doenças do feto e do recémnato de mãe alcoolista, doenças neurológicas e o agravamento de outras doenças psiquiátricas provocado pelo álcool, assim como os agravos decorrentes de acidentes ou violência, o que se aplica a todos os povos.

Pesquisa realizada pelo Instituto Nacional de Abuso de Álcool e Drogas dos EUA (1997) revelou que o uso excessivo de bebida estava presente em $68 \%$ dos homicídios culposos, $62 \%$ dos assaltos, $54 \%$ dos assassinatos e $44 \%$ dos roubos ocorridos. Em relação à violência doméstica, a mesma pesquisa evidenciou que $2 / 3$ dos casos de espancamento de crianças acontecem quando os pais agressores estão embriagados, o mesmo ocorrendo nas agressões entre marido e mulher. No Brasil, pesquisa realizada pelo Cebrid (1996) informou que a análise de mais de 19.000 laudos cadavéricos feitos entre 1986 e 1993 no IML evidencia que, de cada 100 corpos que deram entrada vítimas de morte não natural, 95 tinham álcool no sangue. Experiências municipais de controle e restrição de pontos de venda têm mostrado algum grau de impacto nos indicadores de violência urbana (Prefeitura Municipal de Diadema, 2003). 
Ainda de acordo com o Datasus, e considerando o período compreendido entre 2001 e novembro de 2003, verificamos que os maiores percentuais de internação e gastos são decorrentes do uso prejudicial de álcool - uma variação de $80 \%$, contra o percentual de gastos oriundos do consumo de outras substâncias psicoativas.

\section{Tabela 1 - Morbidade hospitalar no SUS - transtornos mentais e comportamentais}

\begin{tabular}{l|cc|cc|cc}
\hline \multicolumn{5}{c}{ Transtornos Mentais Decorrentes do Uso de Álcool e outras Substâncias Psicoativas - 2001/2003 } \\
\hline \multirow{2}{*}{ MORBIDADES } & \multicolumn{2}{c|}{2001} & \multicolumn{2}{c}{2002} & \multicolumn{2}{|c}{ jan.-nov. 2003} \\
& Internações & Gastos (R\$) & Internações & Gastos (R\$) & Internações & Gastos (R\$) \\
\hline $\begin{array}{l}\text { Transtornos mentais e } \\
\text { comportamentais }\end{array}$ & 98.652 & 69.206 .78 & 96.295 & 74.447 .82 & 95.315 & 67.217 .584 \\
& $(100 \%)$ & $(100 \%)$ & $(100 \%)$ & $(100 \%)$ & $(100 \%)$ & $(100 \%)$ \\
\hline $\begin{array}{l}\text { Transtornos mentais e } \\
\text { comportamentais } \\
\text { devidos ao uso de álcool }\end{array}$ & 84.467 & 60.145 .52 & 78.557 & 62.582 .33 & 76.981 & 55.565 .960 \\
\hline $\begin{array}{l}\text { Transtornos mentais e } \\
\text { comportamentais } \\
\text { devidos ao uso de outras } \\
\text { substâncias psicoativas }\end{array}$ & $(86 \%)$ & $(87 \%)$ & $(82 \%)$ & $(84 \%)$ & $(80 \%)$ & $(83 \%)$ \\
\hline
\end{tabular}

Fonte: Tabnet/Datasus: morbidade hospitalar (2001-2004).

Os dados da tabela confirmam o consenso mundial de que as intervenções voltadas para minimizar os custos decorrentes do uso prejudicial de substâncias psicoativas devem dedicar atenção especial às drogas de uso lícito, especialmente o álcool.

\section{DiReTrizes Gerais da POLÍTICA INTERSETORIAL PARA O ÁlCOOL}

O álcool, como já foi dito aqui, esteve perigosamente ausente das políticas públicas no passado, especialmente em relação à saúde pública. Pela relevância que essa droga apresenta nas variadas conseqüências associadas ao seu consumo, conforme demonstrado aqui, é necessário que se assuma a responsabilidade por essa lacuna, sob pena de não se compreender que o uso de álcool não é um 'problema menor'.

A publicação do documento A Política do Ministério da Saúde para Atenção Integral a Usuários de Álcool e Outras Drogas (Ministério da Saúde, 2003) inaugura o esforço de suprir essa lacuna, sob a lógica da implantação dos 
serviços de atenção, especialmente os CAPS-AD (Centros de Atenção Psicossocial para Usuários de Álcool e outras Drogas).

Os CAPS são o dispositivo estratégico da reforma psiquiátrica no Brasil, e têm a função de, em determinado território, fora do marco hospitalar, articulados a uma rede pública ampliada (serviços públicos de saúde, de apoio social, de educação etc., além de instituições da sociedade), reduzir a iniqüidade no acesso ao tratamento e dar respostas efetivas às necessidades de atenção (Brasil, 2004c).

Existem cinco modalidades de CAPS: CAPS I - funcionam de segunda a sexta-feira, da manhã à tarde, em municípios que têm entre 20 e 70 mil habitantes; CAPS II - semelhantes aos CAPS I, têm uma equipe maior e funcionam em cidades de pequeno a médio porte; CAPS III, serviços de maior porte, que funcionam 24 horas, todos os dias da semana, com um pequeno número de leitos para permanência noturna de pacientes, quando necessário; CAPS-i, destinados à população infanto-juvenil, têm o mesmo porte dos CAPS-II, e CAPSAD. Embora os CAPS-AD sejam os serviços estratégicos para a rede de atenção deste tipo de transtornos, todos os demais CAPS também podem, se necessário, atender usuários de álcool e outras drogas (Brasil, 2004c).

Embora seja uma resposta ainda tímida da saúde pública a este imenso desafio, a rede de CAPS-AD vem se expandindo regulamente, nos últimos dois anos, articulada à rede de demais serviços de saúde mental, e já se constitui em dispositivo importante para enfrentar a questão do acesso ao tratamento. No Tabela 2, vê-se a distribuição atual desses serviços, nos diversos estados do país: 
Tabela 2 - Centros de Atenção Psicossocial, por modalidade e por estado-2004

\begin{tabular}{|c|c|c|c|c|c|c|}
\hline Dispositivos & CAPS I & CAPS II & CAPS III & CAPS-i & CAPS-AD & $\begin{array}{c}\text { Total de } \\
\text { dispositivos } \\
\text { por estado }\end{array}$ \\
\hline \multicolumn{7}{|c|}{ Região Norte } \\
\hline$A C$ & 0 & 0 & 0 & 0 & 1 & 1 \\
\hline AM & 0 & 0 & 0 & 0 & 0 & 0 \\
\hline $\mathrm{AP}$ & 0 & 0 & 0 & 0 & 2 & 2 \\
\hline PA & 7 & 8 & 1 & 1 & 2 & 19 \\
\hline TO & 3 & 2 & 0 & 0 & 0 & 5 \\
\hline $\mathrm{RR}$ & 0 & 0 & 0 & 0 & 1 & 1 \\
\hline RO & 2 & 2 & 0 & 0 & 0 & 4 \\
\hline Subtotal & 12 & 12 & 1 & 1 & 6 & 32 \\
\hline \multicolumn{7}{|c|}{ Região Nordeste } \\
\hline$A L$ & 2 & 4 & 0 & 1 & 0 & 7 \\
\hline $\mathrm{BA}$ & 14 & 17 & 1 & 2 & 3 & 37 \\
\hline CE & 10 & 15 & 0 & 0 & 2 & 27 \\
\hline MA & 4 & 2 & 0 & 0 & 0 & 6 \\
\hline PB & 3 & 3 & 0 & 0 & 2 & 8 \\
\hline $\mathrm{PE}$ & 2 & 12 & 1 & 2 & 2 & 19 \\
\hline $\mathrm{PI}$ & 0 & 0 & 0 & 1 & 1 & 2 \\
\hline $\mathrm{RN}$ & 1 & 5 & 0 & 0 & 2 & 8 \\
\hline SE & 6 & 2 & 1 & 1 & 2 & 12 \\
\hline Subtotal & 42 & 60 & 3 & 7 & 14 & 126 \\
\hline \multicolumn{7}{|c|}{ Região Centro-Oeste } \\
\hline DF & 1 & 0 & 0 & 1 & 0 & 2 \\
\hline GO & 3 & 6 & 0 & 1 & 2 & 12 \\
\hline MT & 8 & 1 & 0 & 1 & 3 & 13 \\
\hline MS & 1 & 3 & 0 & 0 & 0 & 4 \\
\hline Subtotal & 13 & 10 & 0 & 3 & 5 & 31 \\
\hline
\end{tabular}


Tabela 2 - Centros de Atenção Psicossocial, por modalidade e por estado - 2004 (continuação)

\begin{tabular}{l|c|c|c|c|c|c}
\hline Dispositivos & CAPS I & CAPS II & CAPS III & CAPS-i & CAPS-AD & $\begin{array}{c}\text { Total de } \\
\text { dispositivos } \\
\text { por estado }\end{array}$ \\
\hline ES & 3 & 5 & 0 & 0 & 1 & 9 \\
\hline MG & 34 & 28 & 8 & 5 & 2 & 77 \\
\hline RJ & 19 & 28 & 0 & 5 & 4 & 56 \\
\hline SP & 30 & 40 & 14 & 13 & 26 & 123 \\
\hline Subtotal & 86 & 101 & 22 & 23 & 33 & 265 \\
\hline & & \multicolumn{7}{|c|}{ Região Sul } & & \\
\hline PR & 2 & 8 & 1 & 3 & 5 & 19 \\
\hline RS & 30 & 28 & 1 & 4 & 7 & 70 \\
\hline SC & 16 & 12 & 0 & 2 & 2 & 32 \\
\hline Subtotal & 48 & 48 & 2 & 9 & 14 & 121 \\
\hline Total geral & 201 & 231 & 28 & 43 & 72 & 575 \\
\hline
\end{tabular}

Fonte: Brasil, 2004c.

A abordagem da questão do álcool nos impõe uma compreensão ética que deve pautar as ações governamentais. Quanto aos objetivos a serem cumpridos, temos, por um lado, que garantir as condições para que as pessoas façam escolhas responsáveis e autônomas, e, por outro, a obrigação de defender os setores mais vulneráveis da sociedade, notadamente crianças, jovens e adolescentes, em relação ao consumo de bebidas alcoólicas.

De modo geral, os países que têm políticas específicas para o álcool, e a elas aliam os resultados de estudos avaliativos, recomendam que estratégias intersetoriais sejam adotadas levando-se em consideração os seguintes objetivos:

- restringir o acesso e o consumo;

- regular a propaganda;

- reduzir os danos causados pelo álcool.

Publicação recente (Babor et al., 2003) reforça essa noção e fortalece a necessidade do trabalho conjunto e do pragmatismo como eixos de atuação. Da mesma forma, o governo inglês está discutindo diretrizes com o objetivo de diminuir os danos associados ao uso de bebidas alcoólicas (Strategy Unit, 2003).

Algumas iniciativas que privilegiam a taxação e o aumento de preço, a fiscalização e o cumprimento de legislação, a regulação governamental da 
propaganda, além da difusão de informações realistas e isentas de julgamento, estão citadas como ações eficazes e positivas.

No Brasil, o governo Lula, de maneira inédita, tomou para si a missão de discutir essa questão. Um Grupo de Trabalho Interministerial (GTI) foi criado para revisar, propor e discutir a política sobre álcool. Ainda que as causas e conseqüências do uso prejudicial de álcool ultrapassem um campo específico de atuação, a saúde pública tem papel fundamental em quaisquer intervenções a serem implementadas nesse âmbito e, por isso, o ministro da Saúde coordena o GTI, que tem a participação de representantes de outros 14 órgãos federais.

Fazem parte do GTI o Gabinete de Segurança Institucional da Presidência da República (por intermédio da Senad - Secretaria Nacional AntiDrogas), os ministérios da Saúde, Educação, Cidades (principalmente por intermédio do Departamento Nacional de Trânsito), Justiça, Agricultura, Ação Social e Combate à Fome, Fazenda, Comunicação Social, Cultura e a Secretaria Especial de Direitos Humanos.

O desenvolvimento dos trabalhos do GTI apontou para discussões técnicas e políticas também realizadas com outros atores, como representantes da indústria de bebidas, das emissoras de rádio/televisão e com especialistas da comunidade acadêmica.

O resultado desse trabalho, além da necessária articulação intersetorial, se revela na multiplicidade de diretrizes da política, que constitui o eixo condutor das ações de governo para a questão do álcool, assumida em toda a sua complexidade.

\section{DiRetrizes da POLÍTICA 2}

1. O consumo de bebidas alcoólicas, bem como de outros tipos de drogas, sejam elas lícitas ou ilícitas, faz parte da cultura humana desde as épocas mais remotas. Do ponto de vista da saúde pública, o que importa é desenvolver ações intersetoriais que sejam eficazes na redução dos danos à saúde causados pelo consumo prejudicial do álcool e outras drogas, incluídos os psicofármacos.

2 As 26 diretrizes a seguir integram o relatório oficial da primeira parte dos trabalhos do GTI, aprovadas como orientações de governo para a política sobre bebidas alcoólicas (Ministério da Saúde, 2004a). 
2. Dentre todas as drogas lícitas e ilícitas, o consumo prejudicial de bebidas alcoólicas é aquele que mais danos produz à saúde e ao bem-estar, sendo o mais grave do ponto de vista da saúde pública.

3. Entende-se como uso prejudicial de bebidas alcoólicas o consumo que pode acarretar danos à saúde e ao bem-estar da pessoa e dos ambientes sociais. O uso prejudicial guarda relação diretamente proporcional com os padrões de consumo (quantidade, tipo, qualidade, forma e hábitos de uso). Deve ser ressaltado que problemas associados ao uso de álcool podem ocorrer também com o uso eventual ou fortuito.

4. Os danos à saúde e ao bem-estar causados pelo consumo prejudicial de bebidas alcoólicas incluem: a) agravos à saúde física; b) agravos à saúde mental; c) problemas no relacionamento familiar, interpessoal e social; d) problemas relacionados ao trabalho (desempenho, absenteísmo, acidentes, relações interpessoais); e) acidentes de trânsito; f) acidentes domésticos e outros acidentes; g) situações de violência doméstica e outras, em que o álcool pode atuar como desencadeante ou facilitador; h) situações de conflito com a lei.

5. Para os efeitos desta política, é considerada bebida alcoólica toda bebida que contiver 0,5 grau Gay-Lussac ou mais de concentração, incluindo-se aí bebidas destiladas, fermentadas e outras preparações, como a mistura de refrigerantes e destilados, além de preparações farmacêuticas que contenham teor alcoólico significativo.

6. Uma política integral e intersetorial de redução dos danos causados pelo álcool deve contemplar a atenção integral à saúde e à vida, buscando atenuar, minimizar e/ou eliminar todos os danos mencionados.

7. Esta política deve envolver governo e sociedade, em todos os seus segmentos: área cultural e educacional, área sanitária, meios de comunicação, setor produtivo, comércio \& serviços, organizações nãogovernamentais etc.

8. Deve ainda utilizar a lógica ampliada de redução de danos como referencial para as ações políticas, educativas, terapêuticas e preventivas, em todos os níveis.

9. Todos os consumidores têm direito a informações sobre os efeitos do uso prejudicial de álcool, sobre a possibilidade de modificação dos padrões de consumo, e a orientações voltadas para o uso responsável, no sentido da responsabilização e autonomia da pessoa. 
10. É obrigação do governo e da sociedade proteger os segmentos mais vulneráveis ao consumo prejudicial e ao desenvolvimento de hábito e dependência, como as crianças e adolescentes.

11. Da mesma forma, é obrigação do governo e da sociedade adotar medidas, discutidas democraticamente, que atenuem e previnam os danos do álcool em situações específicas, como transportes, ambientes de trabalho, eventos de massa, e em contextos de maior vulnerabilidade.

12. O consumidor deve ser alertado sobre os danos potenciais associados ao consumo de bebidas alcoólicas, bem como sobre os danos diretos à saúde.

13. Recursos educacionais e de comunicação social devem ser utilizados em benefício da melhor informação e conhecimento sobre os danos associados, e ainda sobre os limites do uso que não é prejudicial à saúde.

14. Deve ser implementada uma política integral, intersetorial e inclusiva de atenção aos usuários e dependentes de bebidas alcoólicas, com ações na rede básica de saúde e atendimento na rede hospitalar não-psiquiátrica, quando necessário, além de programas de suporte e reintegração social.

15. A propaganda de bebidas alcoólicas deve ser controlada, de modo a proteger segmentos vulneráveis, como crianças e adolescentes, e a proteger o consumidor de associações indevidas entre o efeito decorrente do consumo de bebidas e estereótipos de sucesso e inserção social que não correspondam à realidade desses usuários.

16. A restrição e o controle devem levar em conta o meio de veiculação da propaganda, sendo diferenciadas para os diversos meios, como rádio, TV, imprensa escrita, cartazes, folhetos, mídia eletrônica etc.

17. O patrocínio de eventos esportivos como meio de propaganda também deve ser objeto de restrição e controle, tendo em vista a proteção de crianças e adolescentes, e da sociedade em geral. A associação entre álcool e eventos esportivos deve ser vista como um problema a ser equacionado.

18. A venda e o consumo devem ser restritos, especialmente em lugares de grande concentração de pessoas, veículos de transporte coletivo, proximidade de estradas, postos de gasolina, escolas, hospitais etc.

19. Devem ser induzidas posturas municipais e outras medidas que restrinjam espacial e temporalmente os pontos de venda e consumo de bebidas alcoólicas. 
20. Ações preventivas de restrição da venda e consumo devem ser realizadas em contextos de maior vulnerabilidade a situações de violência e danos sociais. A venda para menores de 18 anos deve ser objeto de fiscalização rigorosa.

21. Devem ser discutidas as linhas gerais de uma política fiscal que desestimule a produção e o consumo de bebidas alcoólicas.

22. A prevenção é essencial para a saúde pública; devem ser estimuladas, em todo o país, práticas educativas, relativas ao uso de álcool e outras drogas, que estimulem a percepção, a reflexão e a articulação das pessoas sobre a temática em questão, de forma pragmática e responsável.

23. Todos os ministérios do governo devem estar implicados intersetorialmente nas iniciativas voltadas para a educação, a promoção da saúde e de hábitos saudáveis, para o reforço da mudança de padrões de consumo e para a ênfase na responsabilização e no autocuidado.

24. As escolas, sejam de natureza pública ou privada, devem ser local privilegiado para iniciativas de prevenção do consumo de bebidas alcoólicas.

25. Governo, sociedade, empregadores e empregados devem ser chamados a desenvolver e a participar de políticas integrais de prevenção e tratamento dos danos à saúde e ao bem-estar causados pelo consumo de bebidas alcoólicas, respeitados os direitos individuais, a privacidade e a cidadania dos trabalhadores.

26. Os ambientes de trabalho devem ser vistos como locais privilegiados para iniciativas de prevenção do uso prejudicial de bebidas alcoólicas.

\section{AÇÕES CONCRETAS}

O Ministério da Saúde, por intermédio da Área Técnica de Saúde Mental, tem o objetivo de implementar e fortalecer as ações que são específicas no que diz respeito ao consumo de álcool, além de participar de iniciativas intersetoriais sobre o tema.

No campo normativo, já está em discussão a atualização da legislação vigente que regula a propaganda de bebidas alcoólicas no país, como desdobramento dos resultados do GTI. A indústria de bebidas alcoólicas, é necessário reconhecer, implicou-se nessa discussão, buscando influenciála com o lançamento, em 2003, de uma proposta de 'auto-regulamenta- 
ção’ que incorporou algumas das recomendações do GTI. No entanto, é importante ressaltar que avaliações conduzidas por pesquisadores independentes revelam que essas iniciativas, além de serem criações unilaterais e não alcançarem os efeitos buscados pelo governo, apresentam baixa efetividade (Global Alcohol Policy Alliance, 2002).

A necessidade de fortalecer a articulação da rede de atenção à saúde das pessoas que fazem uso de álcool, nos seus diferentes níveis de complexidade, levaram o Ministério da Saúde à discussão do componente hospitalar dessa rede. A criação, em hospitais gerais, de leitos de retaguarda aos casos que necessitam de internação é uma necessidade recorrente dos profissionais que lidam com essa realidade.

Essa referência não está formalizada na maioria das cidades brasileiras, nem no Sistema Único de Saúde. No entanto, ao elaborar critérios baseados na qualificação da equipe, no contingente populacional e na existência de Centros de Atenção Psicossocial Álcool e Drogas (CAPS-AD), visando ao cadastramento dessa nova modalidade de atenção, o Ministério da Saúde responde a uma lacuna existente na rede. A inclusão desse serviço na estrutura do SUS estará vinculada a procedimentos específicos, regulamentados em norma a ser publicada. Os hospitais gerais que já o fazem continuarão a atender os usuários de álcool; porém, após avaliação técnica no âmbito local, serão habilitados novos 'Serviços hospitalares de referência para atenção integral a usuários de drogas e/ou outras drogas', em todas as regiões metropolitanas e municípios com mais de 200.000 habitantes (totalizando, aproximadamente, entre 200 e 220 serviços). ${ }^{3}$

Além dessas ações, a continuação da formação dos profissionais da saúde, a ampliação da rede CAPS-AD, o trabalho intra e interministerial e a colaboração mútua com outras pessoas e organizações atentas a este tema compõem o repertório de iniciativas que visam tanto à inserção do consumo de álcool e das conseqüências a ele associadas na agenda da saúde pública como à construção de respostas eficazes, efetivas e eficientes a esses problemas.

\footnotetext{
3 A adoção do paradigma da redução de danos para a política pública sobre bebidas alcoólicas resultou no convite, ao governo brasileiro, para apresentar as conclusões do Grupo Técnico Interministerial na Conferência Internacional de Redução de Danos e Álcool, realizada em Varsóvia, Polônia, em agosto de 2004. Desde esse encontro, o Brasil faz parte de uma coalizão internacional de promoção de políticas públicas abrangentes, com ênfase na redução de danos, para a questão do álcool, integrada por países do Leste Europeu, da Europa Ocidental e da América Latina.
} 


\section{REFERÊNCIAS BIBLIOGRÁFICAS}

BABOR, T. et al. Alcobol: no ordinary commodity - research and public policy. Oxford: Oxford University Press, 2003.

BUNING, E. et al. Álcool e Redução de Danos: uma abordagem inovadora para países em transição. Brasília: Ministério da Saúde, 2003. (Publicado também em espanhol, pela Junta Nacional de Drogas, do governo do Uruguai. Montevidéu, 2004).

BRASIL. Ministério da Saúde. A Política do Ministério da Saúde para Atenção Integral a Usuários de Álcoole Outras drogas. Brasília: Ministério da Saúde, 2003. (Série E. Legislação de saúde)

BRASIL. Ministério da Saúde. Grupo Técnico Interministerial para a política sobre bebidas alcoólicas. Relatório final. Abril de 2004. Brasília, $2004 a$.

BRASIL. Ministério da Saúde Legislação em Saúde Mental 1990-2004. 5.ed. ampl. Brasília: Ministério da Saúde, 2004b.

BRASIL. Ministério da Saúde. Saúde Mental no SUS: os Centros de Atenção Psicossocial. Brasília: Ministério da Saúde, 2004c.

CARLINI, E. A. et al. I Levantamento Domiciliar sobre o Uso de Drogas Psicotrópicas no Brasil. São Paulo: Cebrid/Unifesp, 2002.

DATASUS. Ministério da Saúde. Banco de Dados do SIH/SUS. Brasilia: Ministério da Saúde, 2004.

GALDURÓZ, J. C.; NOTO, A. R. \& CARLINI, E. A. IV Levantamento sobre o Uso de Drogas entre Estudantes de 1ํ e 2Graus em 10 Capitais Brasileiras - 1997. São Paulo: Cebrid/ Escola Paulista de Medicina, 1997.

GLOBAL ALCOHOL POLICY ALLIANCE. Beverage Alcohol Industry's Social Aspects Organizations: a public health warning, 2002. Disponível em http://www.ias.org.uk/ publications/theglobe/02issue3/globe02issue3.pdf

IPEA, Ministério da Saúde e colab. Impactos Sociais e Econômicos dos Acidentes de Trânsito nas Aglomeraçôes Urbanas (em desenvolvimento).

MELCOP, A. G. \& OLIVEIRA, E. M. Álcoole Trânsito. Recife: Instituto Raid, 1997.

MELCOP, A. G. et al. Impacto do Uso de Álcool e outras Drogas em Vítimas de Acidentes de Trânsito. Brasília: Associação Brasileira dos Detrans (ABDetran), 1997.

MURRAY, C. J. L. \& LOPEZ, A. D. The Global Burden of Disease: a comprehensive assessment of mortality and disability, form diseases, injuries and risk factors in 1990 and projected to 2020. Cambridge: Massachusetts Harvard School of Public Health to World Health Organization and World Bank, 1996. (Global burden of disease and injury series, I)

NATIONAL INSTITUTE ON DRUG ABUSE. Nida Notes, 12(5):3-8, 1997.

ORGANIZAÇÃO MUNDIAL DA SAÚDE. Saúde Mental: nova concepção, nova esperança. Relatório sobre a saúde no mundo 2001. OMS: Genebra, 2001.

PREFEITURA MUNICIPAL DE DIADEMA. Programa de restrição dos pontos de venda de bebidas alcoólicas. Apresentado no Seminário sobre Política Intersetorial sobre Álcool. Ministério da Saúde, Brasília, 25 e 26 de novembro de 2003.

STRATEGY UNIT, 2003. Disponível em: http://www.number-10.gov.uk/files/pdf/ SU\%20interim_report2.pdf 